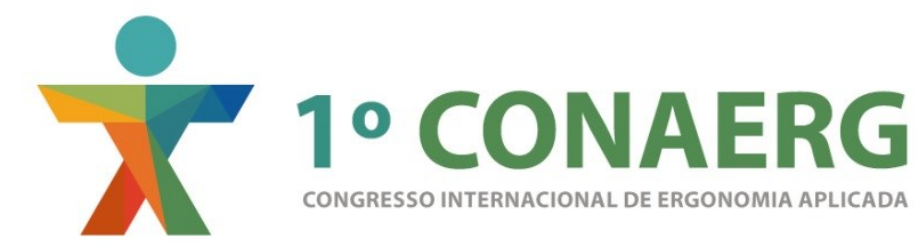

\title{
HABITAÇÕES INTELIGENTES PARA PESSOAS COM DEFICIÊNCIA E DE MELHOR IDADE BASEADA NO PROGRAMA MINHA CASA MINHA VIDA
}

\author{
Raphael de Almeida Bernini (1) \\ Eduardo Ferro dos Santos (2) \\ (1) Universidade de São Paulo / Escola de Engenharia de Lorena \\ Graduação em Engenharia Física \\ e-mail: raphael.ab@alunos.eel.usp.br \\ (2) Universidade de São Paulo / Escola de Engenharia de Lorena \\ Doutorado em Engenharia de Produção \\ e-mail: eduardo.ferro@usp.br
}

\begin{abstract}
RESUMO
Este trabalho tem por objetivo demonstrar uma proposta de um ambiente inteligente de baixo custo para apoio a projetos habitacionais de pessoas com deficiência ou de melhor idade. Trata-se do levantamento dos principais conceitos de vida independente e soluções técnicas de projeto arquitetônico e de automação residencial, buscando alternativas a facilidades mecânicas, sistemas mecatrônicos e monitoramento de variáveis de atenção (mobilidade, assistência à saúde, interface homem-máquina) e suas utilizações como tecnologias assistivas. Se aplica ao desenvolvimento de croquis assistidos por computador de unidades habitacionais de fácil controle e baixo custo, tendo como foco populações de baixa renda.
\end{abstract}

\begin{abstract}
This project has the objetive to develop a smart enviroment of low cost of support housing projects to elderly and disabled people. This work consist in collection of principal concepts of independente life and tecnical solutions of architectural projects and residencial automation, searching for alternatives of mechanical facilities, mechatronics systems and to monitoring both of variables of attention (as mobility, health assistance, man-machine interface) and aplications of assistive tecnologies. The project applies to development of sketches aided by computer of easy control and low cost housing units, focusing on low-income people.
\end{abstract}

\section{INTRODUÇÃO}

A domótica assistiva pode ser definida como a utilização de sistemas mecatrônicos em um ambiente residencial, utilizado para melhorar as atividades de vida diária de pessoas com melhor idade e pessoas com deficiência (BUNEMER, 2014). Estatísticas 
recentes mostram uma tendência de crescimento rápido no número destas pessoas que precisam de ajuda externa em suas tarefas diárias (RAIS, 2013). O cuidado com estas pessoas se torna cada vez mais importante, já que atualmente temos um aumento significativo da população mundial de pessoas acima de 65 anos de idade (melhor idade) (IBGE, 2013) e de pessoas com deficiência (RAIS, 2013). É óbvio que o trabalho de cuidar destas pessoas não pode ser resolvido simplesmente aumentando o número de cuidadores e de planos de saúde. Em uma visão mais otimista, a qualidade de vida das pessoas pode ser melhorada significativamente por meio da inclusão de tecnologias modernas, principalmente através de ambientes inteligentes, sistemas de iteração homem máquina e tecnologia pessoal, sendo que o crescimento destes vem evoluindo na atualidade (FERREIRA, 2010).

Os sistemas inteligentes apresentam-se como uma nova geração tecnológica, em que a computação e as tecnologias de comunicação de dados estão fortemente relacionadas com o monitoramento e controle de entidades do mundo físico. Exemplos incluem: sistemas veiculares e de transporte inteligentes, sistemas de monitoramento de saúde pessoal, sistemas inteligentes de monitoramento residencial, sistemas de manufatura industrial, dentre outros (CHENG \& ATLEE, 2007). Segundo Campbell et al. (2006), essa nova geração de sistemas faz uso intensivo de redes de sensores e tecnologia computacional embarcada e está presente em diversos campos, servindo para nos proporcionar melhores condições em nossas atividades de vida diária. Chamusca (2006) comenta a utilização dos sistemas inteligentes em residências (domótica), constitui-se num campo fértil, seja do ponto de vista de quem procura soluções urgentes para seus problemas e necessidades em casa, quanto do ponto de vista das empresas imobiliárias que recorrem a estes para agregarem valor ao imóvel através de alguns recursos suficientes para atender às expectativas do cliente.

No contexto da proposta desse trabalho, pretende-se utilizar sistemas inteligentes como agente integrador entre a pessoa com deficiência e de melhor idade, com o seu ambiente, criando um projeto de casa enxuta e inteligente que interaja e facilite as atividades de vida diária. A importância deste tipo de tecnologia de apoio se baseia em referências internacionais adotadas, como a SmartBo (ELGER \& FURUGREN, 1998), a Robotic Room (NAKATA et al., 1996), Inteligent Smart Home (JUNG et al., 2005), e a Smart House (STEFANOV et al., 2004).

O trabalho visa então propor conceitos de automação que contribuam com a vida independente de pessoas na melhor idade e pessoas com deficiências em suas residências, e como são vivenciados os processos de atenção à saúde. O trabalho se concentra em projetos de soluções técnicas para esta população em sistemas mecânicos e mecatrônicos. Os projetos incluem sistemas de infraestrutura lógica, robótica em transferência sem esforço do usuário, móveis e acessórios ergonômicos, sistemas de telemetria e telemedicina, ambientes interativos, sistema de segurança, dentre outros. 


\section{DOMÓTICA E TECNOLOGIAS ASSISTIVAS}

As limitações físicas funcionais em pessoas com deficiência e de melhor idade podem manifestar-se das mais diversas formas, e em sua grande maioria, essas formas de deficiência podem excluir indivíduos da sociedade, principalmente do mercado formal de trabalho. O Ministério do Trabalho e Emprego divulgou uma estatística em 2013 mostrando que dos 49 milhões de vínculos trabalhistas ativos, apenas 358 mil eram de pessoas deficientes $(0,73 \%$ no total), sendo que destas $51 \%$ representavam pessoas com deficiências físicas (RAIS, 2013).

Devido ao alto custo e complexidade no desenvolvimento de tecnologias proprietárias que promovem a inclusão social, o deficiente tem grandes dificuldades em suas atividades de vida diária e permanece excluído da sociedade e do trabalho. A utilização da automação permite a padronização e a flexibilização de sistemas, fazendo com que seja usada dentro do ambiente doméstico como incremento na qualidade de vida das pessoas. Os recursos tecnológicos disponíveis, ou em fase de desenvolvimento, abrem oportunidades para um novo caminho no estudo e nas aplicações da automação para o nível dos edifícios, residências e ambientes de trabalho (ALIEVI, 2008).

O desenvolvimento de estudos nessa área pode ser caracterizado como essenciais não só pela sua contribuição acadêmica como também pela sua contribuição social. Sistemas inteligentes como tecnologia assistiva podem ser considerados como grandes oportunidades de inclusão produtiva e social, no apoio à autonomia de pessoas com deficiência física e de melhor idade, possibilitando melhoria da acessibilidade e prerrogativas antes não alcançadas.

O programa minha casa minha vida (PMCMV) é um programa social do Governo Federal que foi lançado em março de 2009, e tem como objetivo possibilitar que as famílias de baixa renda possam ter acesso à casa própria. Além da contribuição social, o programa também gerou muitos empregos no setor de construção civil (CEF, 2016). Sua importância no trabalho se dá pelo motivo de o programa poder oferecer ambientes inteligentes a pessoas de baixa renda. Este é usado neste trabalho para poder oferecer casa própria com infraestrutura física e lógica adequada para melhorar a qualidade de vida e atividades de pessoas com deficiência e de melhor idade, além de também oferecer um subsídio do governo na construção, oferecendo baixo custo para a aquisição do imóvel.

O RAIS (Relação Anual de Informações Sociais) divulgou uma estatística mostrando que dos 49 milhões de vínculos trabalhista ativos, apenas 358 mil eram de pessoas deficientes $(0,73 \%$ do total), sendo que destas $51 \%$ representavam pessoas com deficiências físicas (RAIS, 2013). De 2012 para 2013 houve um aumento de 8,33\% no número de pessoas deficientes, fazendo um acréscimo de 27,5 mil empregos. Dos 358 mil vínculos trabalhistas, 232 mil eram do gênero masculino e 126 mil do gênero feminino.

A palavra Domótica vem de duas palavras latinas: Domus, que significa casa, e da robótica, ou seja, significa em outros termos: robótica doméstica. Está relacionada à instalação e controle de tecnologias em residências que pretendem aumentar a 
qualidade de vida, segurança e viabilizar que o próprio usuário possa programa-la da forma que quiser (DOMINGUES, 2013).

Atualmente ela conta com centenas de soluções para diversos usuários, indo desde um simples sistema de alarme até sofisticadas soluções ao nível mundial, principalmente nos Estados Unidos, líder nesta categoria. A domótica apresenta algumas vantagens ao serem instaladas nas residências, permitindo que elas sejam mais modernas, práticas e de fácil uso, econômica energeticamente e mais segura. Devido ao surgimento e uso de tecnologias como computadores pessoais, internet, telefonia móvel, houve uma entrada maior dos consumidores no ramo da tecnologia e a partir disso as tecnologias residenciais ganharam mais espaço e força.

\section{PROJETO DO AMBIENTE}

O projeto visa um modelo de uma casa em que através da automação (domótica) o indivíduo consiga usufruir de conforto, segurança e de alta tecnologia, tornando seu estilo de vida melhor. Tendo como referência a norma técnica de acessibilidade NBR 9050 pode-se elaborar um modelo de casa de modo que ficasse em concordância com a norma e suas dimensões de acesso. Além dessa norma, foi usado outro critério de referência: as especificações mínimas de casas construídas pelo PMCMV. Essas especificações podem ser encontradas no site da caixa (CEF, 2016) e algumas delas serão modificadas para que haja concordância com a norma da ABNT 9050.

O PMCMV possui plantas padrões de casa que ela constrói, além de também descrever algumas especificações mínimas de mobiliários, cômodos, pontos de iluminação, etc. Na figura 1 é ilustrada uma planta padrão tipologia do PMCMV, que possui área total de $35 \mathrm{~m}^{2}$ e área útil de $32 \mathrm{~m}^{2}$ e possui largura de passeio de $0,50 \mathrm{~m}$. Essa planta não é adequada para acesso de pessoas com deficiência e idosos, pois não possui as características necessárias para isso conforme cita a norma da ABNT 9050 e não possui as dimensões necessárias para a perfeita locomoção e movimentação dessas pessoas, sendo então necessárias alterações na planta para que o acesso possa acontecer.

Seguindo nessa linha de referência, a figura 2 ilustra a planta proposta da casa. Ela é composta por dois quartos, um banheiro, sala de estar e uma cozinha, possuindo uma área total de $67,9 \mathrm{~m}^{2}$ e uma área útil de $60,1 \mathrm{~m}^{2}$, a espessura das paredes é de $15 \mathrm{~cm}$ e altura de 2,70 m. Altura de todas as portas é de 2,10 m e possuem largura de 1,0 m e espessura de $35 \mathrm{~mm}$, a janela do banheiro tem $0,6 \mathrm{~m}$ de largura/comprimento, $15 \mathrm{~cm}$ de espessura e instalada a 1,00 m do piso, e as demais janelas da casa tem 1,0 m de largura/comprimento, $15 \mathrm{~cm}$ de espessura e instaladas a $1,0 \mathrm{~m}$.

Foi realizada uma análise das especificações mínimas da casa construída pelo PMCMV e foram modificadas algumas dessas especificações para que a casa pudesse oferecer o máximo de conforto, estilo de vida e ficasse de acordo com a norma da ABNT. No quadro 1 mostra-se quais eram as especificações do programa e em seguida o que foi mudado e o motivo pela qual houve a mudança. 
Figura 1 - Planta de casa tipologia 1 do PMCMV

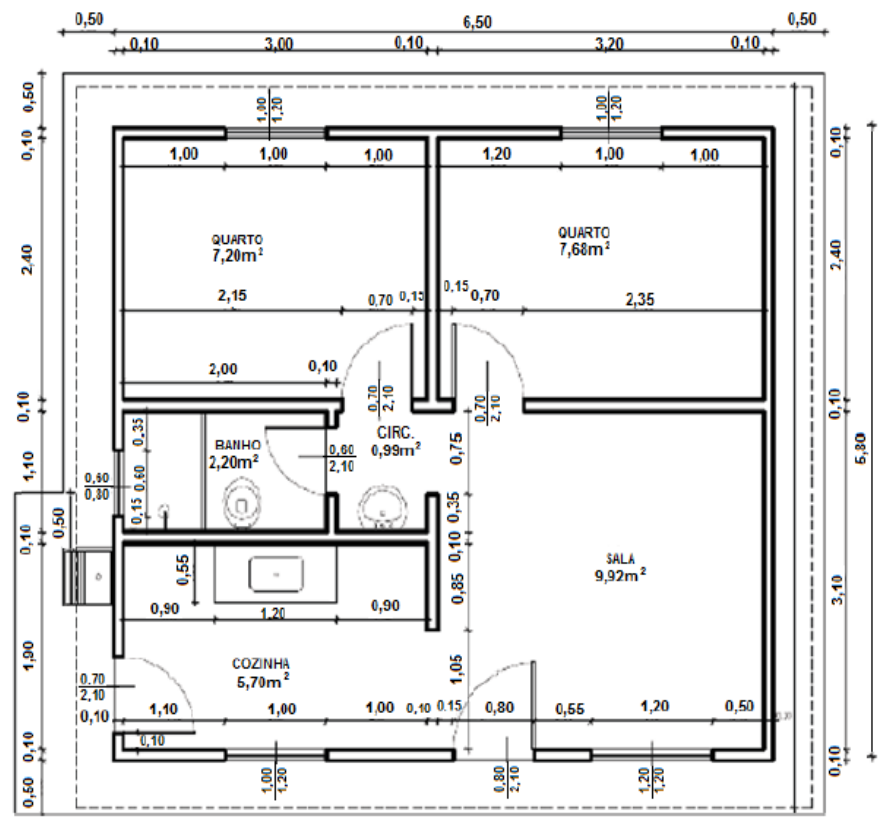

Fonte: CEF, 2016

Figura 2 - Planta do projeto da casa

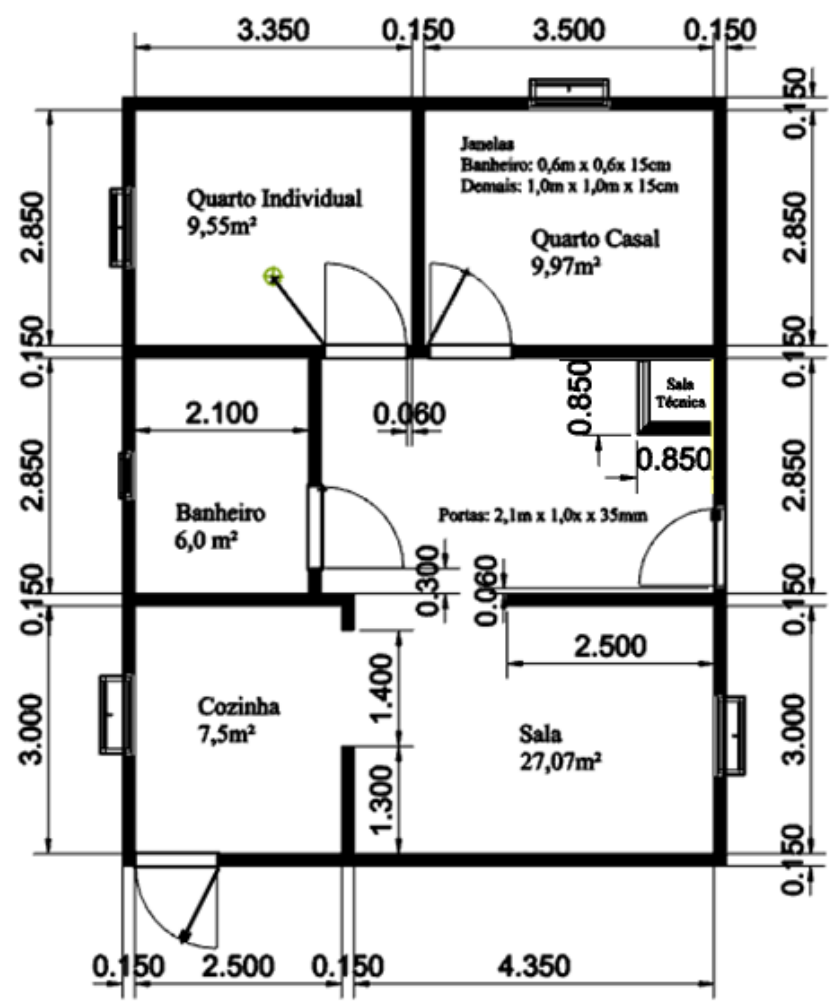

Fonte: Autor 
Quadro 2 - Mudanças das especificações do PMCMV para o projeto

\begin{tabular}{|c|c|c|c|}
\hline Item & PMCMV & Nova Proposta & Comentários \\
\hline $\begin{array}{l}\text { Dimensões } \\
\text { dos } \\
\text { cômodos: } \\
\text { Quarto de } \\
\text { casal. }\end{array}$ & $\begin{array}{l}1 \text { cama }(1,40 \mathrm{~m} \times 1,90 \mathrm{~m}) ; 1 \\
\text { criado-mudo }(0,50 \mathrm{~m} \times 0,50 \mathrm{~m}) \\
\text { e } 1 \text { guarda-roupa }(1,60 \mathrm{~m} \times \\
0,50 \mathrm{~m}) \text {. Circulação mínima } \\
\text { entre mobiliário e/ou paredes } \\
\text { de } 0,5 \mathrm{~m} \text {. }\end{array}$ & $\begin{array}{l}\text { Comprimento de } 3,5 \mathrm{~m} \text { e } \\
\text { largura de } 2,85 \mathrm{~m} \text { onde haverá } \\
\text { espaço para os moveis e para } \\
\text { a movimentação de pessoas }\end{array}$ & $\begin{array}{l}\text { Inserido um sensor de } \\
\text { arrombamento na janela, } \\
\text { uma tomada inteligente e } \\
\text { uma lâmpada inteligente. }\end{array}$ \\
\hline $\begin{array}{l}\text { Quarto } \\
\text { para duas } \\
\text { pessoas }\end{array}$ & $\begin{array}{l}2 \text { camas }(0,80 \mathrm{~m} \times 1,90 \mathrm{~m}) ; 1 \\
\text { criado-mudo }(0,50 \mathrm{~m} \times 0,50 \mathrm{~m}) \\
\text { e } 1 \text { guarda-roupa }(1,50 \mathrm{~m} \times \\
0,50 \mathrm{~m}) \text {. Circulação mínima: } \\
\text { entre as camas de } 0,80 \mathrm{~m} . \\
\text { Demais circulações, mínimo } \\
\text { de } 0,50 \mathrm{~m} \text {. }\end{array}$ & $\begin{array}{l}\text { Comprimento de } 3,35 \mathrm{~m} \text { e } \\
\text { largura de } 2,85 \mathrm{~m} \text {, onde o } \\
\text { espaço é melhor aproveitado } \\
\text { novamente. }\end{array}$ & $\begin{array}{l}\text { Inserido um sensor de } \\
\text { arrombamento na janela, } \\
\text { uma tomada inteligente e } \\
\text { uma lâmpada inteligente. }\end{array}$ \\
\hline Cozinha & $\begin{array}{l}\text { Largura mínima da cozinha: } \\
1,80 \mathrm{~m} \text {. Quantidade mínima de } \\
\text { equipamentos: pia }(1,20 \mathrm{~m} \times \\
0,50 \mathrm{~m}) \text {; fogão }(0,55 \mathrm{~m} x \\
0,60 \mathrm{~m}) \text {; e geladeira }(0,70 \mathrm{~m} \times \\
0,70 \mathrm{~m}) \text {. Previsão para armário } \\
\text { sob a pia e gabinete. }\end{array}$ & $\begin{array}{l}\text { Possui largura de } 2,35 \mathrm{~m} \text { e } \\
\text { comprimento de } 3,0 \mathrm{~m} \text {, possui } \\
\text { uma porta que dá acesso ao } \\
\text { lado externo, uma janela e } \\
\text { uma abertura (de } 1,0 \mathrm{~m} \text { de } \\
\text { comprimento) que dá } \\
\text { passagem direta com a sala } \\
\text { de estar }\end{array}$ & $\begin{array}{l}\text { Inserido dois sensores de } \\
\text { arrombamento: na janela } \\
\text { e na porta, uma tomada } \\
\text { inteligente e uma } \\
\text { lâmpada inteligente. }\end{array}$ \\
\hline $\begin{array}{l}\text { Sala de } \\
\text { estar }\end{array}$ & $\begin{array}{l}\text { Largura mínima sala de } \\
\text { estar/refeições: } 2,40 \mathrm{~m} \text {. } \\
\text { Quantidade mínima de } \\
\text { móveis: sofás com número de } \\
\text { assentos igual ao número de } \\
\text { leitos; mesa para } 4 \text { pessoas; e } \\
\text { Estante/Armário TV. }\end{array}$ & $\begin{array}{l}\text { Possui comprimento de } 6 \mathrm{~m} \text { e } \\
\text { largura de } 4,5 \mathrm{~m} \text {. Possui duas } \\
\text { portas: uma dá acesso à área } \\
\text { exterior e a outra na entrada } \\
\text { da casa; e possui também } \\
\text { duas janelas. }\end{array}$ & $\begin{array}{l}\text { Inserida duas tomadas } \\
\text { inteligentes, duas } \\
\text { lâmpadas inteligentes, um } \\
\text { sensor de presença, duas } \\
\text { câmeras IP, um sensor de } \\
\text { incêndio, uma fechadura } \\
\text { eletrônica na porta, um } \\
\text { sensor de arrombamento } \\
\text { na janela e um espaço } \\
\text { para tele saúde. }\end{array}$ \\
\hline Banheiro & $\begin{array}{l}\text { Largura mínima do banheiro: } \\
1,50 \text { m. Quantidade mínima: } 1 \\
\text { lavatório sem coluna, } 1 \text { vaso } \\
\text { sanitário com caixa de } \\
\text { descarga acoplada, } 1 \text { box com } \\
\text { ponto para chuveiro }-(0,90 \mathrm{~m} \\
\text { x } 0,95 \mathrm{~m}) \text { com previsão para } \\
\text { instalação de barras de apoio } \\
\text { e de banco articulado, } \\
\text { desnível máx. } 15 \mathrm{~mm} ; \\
\text { assegurar a área para } \\
\text { transferência ao vaso sanitário } \\
\text { e ao box. }\end{array}$ & $\begin{array}{l}\text { Possui comprimento de } 2,85 \mathrm{~m} \\
\text { e largura de } 2,2 \mathrm{~m} \text {, e possui } \\
\text { uma janela de } 0,6 \mathrm{~m} \times 0,6 \mathrm{~m} \times \\
15 \mathrm{~cm} \text { instalada a } 1,70 \mathrm{~m} \text { do } \\
\text { piso. }\end{array}$ & $\begin{array}{l}\text { Inserido um sensor de } \\
\text { arrombamento na janela, } \\
\text { uma tomada inteligente e } \\
\text { uma lâmpada inteligente. }\end{array}$ \\
\hline $\begin{array}{l}\text { Área de } \\
\text { serviço }\end{array}$ & $\begin{array}{l}\text { Quantidade mínima: } 1 \text { tanque } \\
(0,52 \mathrm{~m} \times 0,53 \mathrm{~m}) \text { e } 1 \text { máquina } \\
\text { de lavar roupas Ârea de } \\
\text { Serviço }(0,60 \mathrm{~m} \times 0,65 \mathrm{~m})\end{array}$ & $\begin{array}{l}\text { Compreende em um passo de } \\
1,7 \mathrm{~m} \text { das paredes da casa. } \\
\text { Manteremos neste caso o } \\
\text { tanque e a máquina de lavar }\end{array}$ & $\begin{array}{l}\text { A área externa precisou } \\
\text { ser aumentada para } \\
\text { poder facilitar o acesso e } \\
\text { movimentação. }\end{array}$ \\
\hline $\begin{array}{l}\text { Característi } \\
\text { cas gerais: } \\
\text { Área útil }\end{array}$ & $\begin{array}{l}35 m^{2} \text { de área total e } 32 m^{2} \text { de } \\
\text { área útil }\end{array}$ & $\begin{array}{l}67,9 \mathrm{~m}^{2} \text { de área total e } 60,1 \mathrm{~m}^{2} \\
\text { de área útil }\end{array}$ & $\begin{array}{l}\text { Essa mudança se deve } \\
\text { ao fato de ter aumentado } \\
\text { as medidas para a } \\
\text { manobra e circulação. }\end{array}$ \\
\hline
\end{tabular}




\begin{tabular}{|c|c|c|c|}
\hline Portas & $\begin{array}{l}\text { Portas em madeira ou } \\
\text { metálica. Batente em aço ou } \\
\text { madeira desde que possibilite } \\
\text { a inversão do sentido de } \\
\text { abertura das portas. Vão livre } \\
\text { de } 0,80 \mathrm{~m} \times 2,10 \mathrm{~m} \text { em todas as } \\
\text { portas. }\end{array}$ & $\begin{array}{l}1,0 \mathrm{~m} \text { de abertura e } 2,10 \mathrm{~m} \text { de } \\
\text { altura em todas elas e } \\
\text { espessura de } 35 \mathrm{~mm} \text {. O } \\
\text { material usado será o WPC } \\
\text { (madeira plástica) }\end{array}$ & $\begin{array}{l}\text { O tamanho da porta pode } \\
\text { ser aumentado devido à } \\
\text { circulação de cadeirantes } \\
\text { e o material para que } \\
\text { fosse resistente aos } \\
\text { impactos. }\end{array}$ \\
\hline Janelas & $\begin{array}{l}\text { Em aço ou madeira. Vão de } \\
1,20 \mathrm{~m}^{2} \text { nos quartos e } 1.50 \mathrm{~m}^{2} \\
\text { na sala, sendo admissível uma } \\
\text { variação de até } 5 \% \text {. }\end{array}$ & $\begin{array}{l}\text { Tem dimensões de } 1,0 \mathrm{~m} \times \\
1,0 \mathrm{~m} \times 0,15 \mathrm{~m} \text { a uma altura de } \\
1,0 \mathrm{~m} \text { do piso, com exceção } \\
\text { do banheiro que tem } 0,60 \mathrm{~m} \times \\
0,60 \mathrm{~m} \times 0,15 \mathrm{~m} \text { e uma altura } \\
\text { de } 1,8 \mathrm{~m} \text { do piso. Pode ser de } \\
\text { madeira ou aço }\end{array}$ & $\begin{array}{l}\text { O tamanho das janelas e } \\
\text { altura em relação ao piso } \\
\text { foram escolhidas devido } \\
\text { ao cone de visão do } \\
\text { cadeirante. }\end{array}$ \\
\hline Pisos & $\begin{array}{l}\text { Cerâmico em toda a área } \\
\text { interna da unidade, com } \\
\text { rodapé, e desnível máximo de } \\
15 \mathrm{~mm} .\end{array}$ & Pisos antiderrapantes & $\begin{array}{l}\text { Propõe-se pisos } \\
\text { antiderrapantes para } \\
\text { evitar possíveis quedas } \\
\text { dos residentes. }\end{array}$ \\
\hline $\begin{array}{l}\text { Instalações } \\
\text { elétricas: } \\
\text { Tomadas }\end{array}$ & $\begin{array}{l}2 \text { na sala, } 4 \text { na cozinha, } 1 \text { na } \\
\text { área de serviço, } 2 \text { em cada } \\
\text { dormitório, } 1 \text { tomada no } \\
\text { banheiro e mais } 1 \text { tomada } \\
\text { para chuveiro elétrico }\end{array}$ & $\begin{array}{l}\text { Quarto solteiro: } 3 \text { tomadas; } \\
\text { Sala: } 4 \text { tomadas; Cozinha: } 4 \\
\text { tomadas; Banheiro: } 3 \\
\text { tomadas; Quarto Casal: } 3 \\
\text { tomadas. }\end{array}$ & $\begin{array}{l}\text { Os tamanhos dos } \\
\text { cômodos mudaram, logo } \\
\text { pode-se mudar o número } \\
\text { de tomadas, seguindo } \\
\text { norma de instalações } \\
\text { elétricas NBR5410. }\end{array}$ \\
\hline $\begin{array}{l}\text { Números } \\
\text { de pontos } \\
\text { diversos }\end{array}$ & $\begin{array}{l}1 \text { ponto de telefone, } 1 \text { ponto } \\
\text { de antena }\end{array}$ & $\begin{array}{l}2 \text { pontos para telefone, } 3 \text { para } \\
\text { antena }\end{array}$ & $\begin{array}{l}\text { Decidiu-se aqui colocar } \\
\text { uma TV por quarto, um } \\
\text { telefone no quarto e na } \\
\text { sala, fora a TV da sala. }\end{array}$ \\
\hline $\begin{array}{l}\text { Pontos de } \\
\text { iluminação }\end{array}$ & 1 ponto em cada ambiente & $\begin{array}{l}\text { Quarto solteiro: } 1 \text { ponto; Sala: } \\
4 \text { pontos; Cozinha: } 1 \text { ponto; } \\
\text { Banheiro: } 1 \text { ponto; Quarto } \\
\text { casal: } 1 \text { ponto. }\end{array}$ & $\begin{array}{l}\text { Propõe-se a mudança o } \\
\text { número de pontos devido } \\
\text { a mudança do tamanho } \\
\text { dos cômodos, seguindo a } \\
\text { norma de instalações } \\
\text { elétricas NBR } 5410 \text {. }\end{array}$ \\
\hline Geral & $\begin{array}{l}\text { Tomadas baixas a } 0,40 \mathrm{~m} \text { do } \\
\text { piso acabado, interruptores, } \\
\text { interfones, campainha e outros } \\
\text { a } 1,00 \mathrm{~m} \text { do piso acabado. }\end{array}$ & $\begin{array}{l}\text { Aqui as tomadas, interruptores } \\
\text { e geral estarão a uma altura } \\
\text { do piso conforme já dito na } \\
\text { norma ABNT } 9010 \text {. }\end{array}$ & $\begin{array}{l}\text { Aqui as mudanças podem } \\
\text { ser feitas segundo as } \\
\text { regras do meio físico para } \\
\text { acesso ao cadeirante. }\end{array}$ \\
\hline
\end{tabular}

Fonte: Autor

Em toda automação da casa pode-se ser usado o sistema de cabeamento estruturado, lembrando que podem ser implementadas várias soluções em vez de uma única solução. Como já dito, este sistema visa a comunicação entre os dispositivos eletrônicos, os computadores e os dispositivos de comunicação da casa. Valendo ressaltar que o sistema suporta transmissão de dados, áudio, vídeo, telefonia e automação.

O sistema conta com um Quadro de Automação Central (QAC) onde será o ponto de acesso dos usuários para o controle do ambiente, este ponto deverá ser instalado em um ponto estratégico do ambiente, que no caso aqui será na Sala Técnica. Pode ser 
utilizada também uma instalação centralizada que poderá contar com Arduino como CLP e placas de relés (potência) para dar os comandos necessários.

Alguns equipamentos e dispositivos poderão ser utilizados, seguindo as categorias: equipamentos eletrodomésticos e eletrônicos, equipamentos de segurança e equipamentos de saúde.

Dentre os equipamentos eletrodomésticos e eletrônicos, que são os mais básicos de uma residência, entre eles temos geladeiras, TV, computadores, vídeo game, freezer, lâmpadas, entre outros. O controle deles pode ser feito de diversas maneiras, porém é vantajoso procurar por uma única solução em que é possível controlar, de maneira geral, todos esses equipamentos da casa. Pode-se utilizar alguns equipamentos que certamente irão fazer a diferença no dia-a-dia do usuário e que poderão ajuda-lo em realizar certas tarefas, além de também poder ajudar no controle e no consumo de energia dos equipamentos.

Para ajudar na limpeza do ambiente o ideal seria contar com a ajuda de robôs que tem a função de limpar o piso, recolher a sujeira, aspirar e passar um pequeno pano de forma controlada e/ou autônoma. A maioria desses robôs conta com, além das funções de limpeza, um controle remoto em que a pessoa pode controlar, especificar um horário de função, colocar tempo de funcionamento, velocidade e outras funções. Possui autonomia de energia de algumas horas, alguns possuem baixo nível de ruído, possuem sensores ópticos e mecânicos para desviar de paredes e objetos, e também podem subir desníveis de poucos centímetros.

O controle sobre as lâmpadas da casa é outro fator que pode ajudar o usuário. Elas são recentes e tem como objetivo o controle das lâmpadas tanto como evitar gasto de energia. A maioria delas são lâmpadas LEDs, o que já contribui com a diminuição do consumo de energia pelas lâmpadas, além de durarem muito mais que as lâmpadas comuns. O controle delas é feito via smarthphone (iOS e Android) e/ou tablet através do bluetooth ou do próprio Wi-fi, utilizando-se de um aplicativo que pode ser baixado e instalado.

As tomadas inteligentes são soluções para o controle do funcionamento dos aparelhos eletrodomésticos e eletrônicos, além de também serem usadas para diminuir o consumo de aparelhos que ficam ligados nas tomadas no modo Stand by.

A comunicação entre a interface e as tomadas se dá, principalmente, por via wireless. Algumas empresas utilizam o Wi-fi como comunicação, outras como, o Z-Wave, utilizam um transmissor que possui frequência própria (JUNIOR, 2012).

Os equipamentos de segurança são importantes elementos que servem para proteger o residente sobre diversos riscos que podem colocar em perigo sua integridade física e psicológica. Para isso, pode-se utilizar sensores e dispositivos que evitarão esses riscos, como: Sensor de incêndio/gás, sensor de presença, sensor de arrombamento, câmeras e painel de abertura da porta de entrada. $O$ controle desses aparelhos pode são feitos usando uma linguagem de programação por um CLP, como o Arduino, através do sistema de cabeamento estruturado. 
Para se evitar riscos de incêndio ou mesmo detectar gás são utilizados sensores de incêndio. Esses sensores detectam a fumaça do incêndio e avisam o residente através de uma sirene incorporada quando é detectado a fumaça. Pode-se também fazer com seja mandado um sinal de alerta para as centrais de incêndio que irão ao local verificar

Os sensores de presença podem ser usados para alertar quando intrusos entram nas casas. A maioria deles usam um sensor infravermelho que irão detectar movimento de pessoas na casa, utilizando ou o método de detectar calor de pessoas ou por reflexão das ondas de infravermelho. Ao detectar o movimento de pessoas, o sensor irá acionar uma carga que mandará um sinal que pode ser de sirene de alerta e/ou até mesmo para centrais avisando sobre ladrões. Para o projeto iremos enviar este sinal ao Arduino que acionará uma sirene e alertará as centrais através de um Shield de GSM GPRS. Com este shield pode-se enviar alertas informando estado de um sensor ou de um sistema de alarme, fazer chamadas telefônicas e automatizar algum processo que envolva telefonia. Uma outra funcionalidade para esses sensores é o de ligar cargas, principalmente lâmpadas, ao detectarem presença de pessoas em determinados cômodos da casa. Essa função pode ser utilizada também para economizar energia elétrica, desligando a carga após o tempo de regulagem do sensor.

Os sensores de arrombamento são usados em janelas, portas, gavetas, quando alguém tenta abri-las de maneira forçada e por isso podem servir como auxilio para a proteção de pessoas dentro da casa. Por mais que se tenha o sensor de presença é indicado que também seja colocado o sensor de arrombamento na casa, caso o de presença não detecte a pessoa. Existem no mercado diversos tipos desses sensores, porém os mais utilizados para portas e janelas são os sensores magnéticos.

Outra aliada que favorece a segurança da casa é a câmera de vigilância. Com ela podemos ter acesso ao vivo e gravado sobre a movimentação da casa, dos horários, etc. Ela pode ser uma ótima ferramenta para quando pessoas desconhecidas entrarem nas casas. Dos diversos tipos de câmeras que existem, a que traz maior vantagem e custo-benefício a longo prazo são as câmeras IP. As câmeras IP são câmeras de vídeo digital que pode ser monitorada através da internet. Elas possuem dispositivos e sistema de carrinho (movimentação), LEDs, visão noturna, gravação remota e microfone que se conectam à rede sem fio, podendo ser monitorada em diversos locais através de um $\mathrm{PC}$ conectado à rede.

A última parte do sistema de segurança é a fechadura eletrônica, ela será usada principalmente para abertura da porta principal da casa e também de qualquer porta que tenha acesso à casa.

Os equipamentos de saúde serão os responsáveis pela monitoração do estado clínico do paciente, além de também ser um mecanismo em que o paciente terá consultas médicas online, passando apenas seus dados clínicos como pressão, ritmo cardíaco, glicose, através de diversos aparelhos de medida. Esse sistema é chamado de tele saúde e tem como objetivo ter atendimento médico em casa, evitando com que o paciente tenha que se deslocar para o consultório, onde apenas será obrigatório a ida ao consultório em casos emergenciais. Esse sistema é composto por um computador/tablet onde o paciente terá uma conversar online com o médico. Além 
disso contará com dispositivos para medição de pressão, glicose, ritmo cardíaco, que passarão os dados de leitura para o médico. Esse sistema pode ser montado no quarto do usuário ou na sala.

Outro dispositivo que poderia ajudar é os organizadores de remédios com alarme. Eles têm como objetivo de organizar os remédios na medida certa e avisar o paciente quando ele deve ingeri-los.

Dentre os diversos tipos de acidentes que ocorrem com idosos e pessoas com deficiências, o que mais acontece e que causa muitos problemas sérios de saúde são as quedas. Segundo Ribeiro (2015) $79 \%$ das quedas com idosos acontecem em casa. Deles apenas $30 \%$ caem uma vez ao ano e $2 / 3$ das pessoas caem uma segunda vez em seis meses. Com esses dados devemos ter alguma medida de segurança antiqueda assim como também um dispositivo eletrônico que possa detectar quando um idoso/cadeirante cair, e com isso possa-se alertar o médico e os familiares responsáveis sobre o acidente que acabou de acontecer.

Para detectar a queda poderá ser utilizado um acelerômetro. Este dispositivo é usado para medir a aceleração através do movimento (posicionamento) do mesmo; é utilizado em diversas aplicações como, por exemplo, é usado em celulares que detectam inclinação do aparelho, é usado em notebooks que travam o disco rígido durante uma queda, também é usado em controles de vídeo game como o Nintendo Wii, etc. $\mathrm{O}$ acelerômetro pode ser instalado na própria cadeira de rodas ou pode ser colocada na cintura por uma cinta. Ao detectar uma queda, o Arduino pode enviar mensagens de texto para os responsáveis utilizando um Shield GSM GPRS.

Sabendo-se das assistências asseguras pela automação por sensores, a figura 3 mostra serão instalados na casa. Não há nenhum tipo de norma ou regra para a localização dos sensores e equipamentos, porém alguns devem ser colocados em certos locais como as lâmpadas inteligentes, os sensores de arrombamento, etc.

Figura 3 - Localização dos equipamentos no ambiente

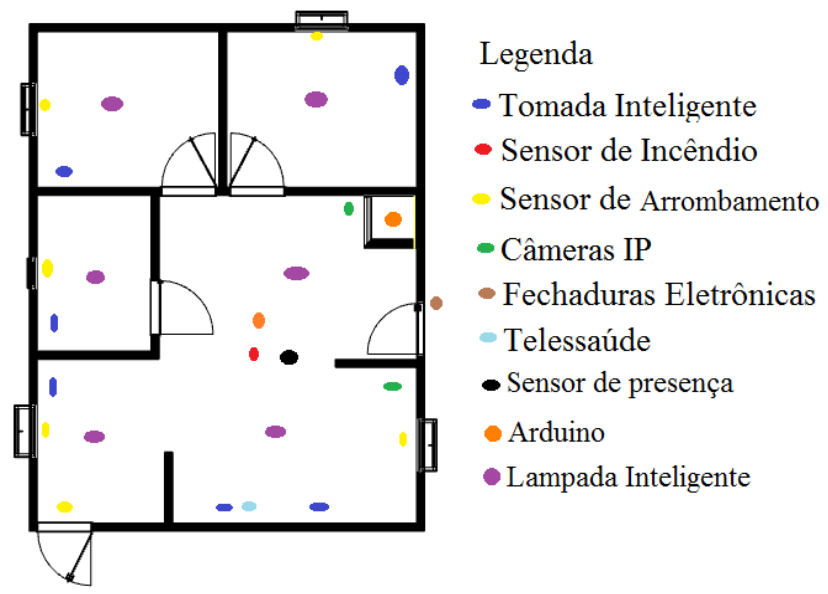

Fonte: Autor

No projeto foi levado em conta o uso de espaços mínimos que no final proporcionam um custo mínimo sem perda de qualidade. A área total mudou de $35 \mathrm{~m}^{2}$ para $67,9 \mathrm{~m}^{2}$, 
um aumento de 94\%. A parte elétrica também sofreu mudança, possuindo agora um sistema de automação adequado, além de poder comportar agora vários dispositivos e equipamentos que irão ajudar pessoas nas suas atividades e melhorar a qualidade de vida e saúde.

\section{CONCLUSÕES E CONSIDERAÇÕES FINAIS}

Neste trabalho foi realizado um estudo dos diversos sistemas que podem ser implementados em uma residência, e que podem ser usados para trazer uma alta qualidade de vida e conforto para pessoas com necessidades especiais e idosos. Conclui-se então que projetos de habitações autônomas junto com programas sociais podem ser usados para melhorar a qualidade de vida de pessoas deficientes/idosas de baixa renda. Também se conclui que esses sistemas utilizados ainda devem ser apreciados pelo mercado brasileiro, pois o mercado ainda não enxerga o grande potencial que essas tecnologias podem oferecer aos usuários e à comunidade em geral.

Para trabalhos futuros que tenham tema relacionado com a este trabalho realizado, pode-se sugerir as seguintes propostas: Investigar diversos outros sistemas de automação residencial que existem no mercado e que podem ser utilizados para trabalhos como este; Investigar a possibilidade de união de diversos tipos de sistemas de automação em um único projeto, avaliando o custo benefício; Estender a proposta do projeto para outros grupos de pessoas que também possam se beneficiar com o projeto, como deficientes visuais, auditivos e outros; Pesquisar outros programas sociais que também podem ser inseridos no projeto e assim oferecer outras possibilidades e melhorias; Propor outros equipamentos e dispositivos que possam ser usados no ambiente, sendo eles utilizados para cada situação que o projeto estiver precisando; Propor um projeto de automação residencial para casas que tenham configurações diferentes, como casas com dois andares, com jardim, casas rurais, etc.

\section{REFERÊNCIAS BIBLIOGRÁFICAS}

ALIEVI, C.A. Automação residencial com a utilização de Controlador Lógico Programável. Trabalho de Conclusão de Curso para aquisição do título de Ciência da Computação. Centro Universitário FEEVALE, Nova Hamburgo, 2008.

ABNT - Associação Brasileira de Normas Técnicas. NBR 9050: Acessibilidade a edificações, mobiliário, espaços e equipamentos urbanos. Rio de Janeiro, 2004.

BUNEMER, R. Domótica assistiva utilizando sistemas integrados de supervisão e controle. 2014, 163f. Dissertação (Mestrado em Engenharia Mecânica) - Escola de Engenhari Mecânica, Faculdade Estadual de Campinas, Campinas, 2014.

CAMPBELL, J.; GOLDSTEIN, S. and MOWRY, T. Cyber-Physical Systems. Position Paper in NSF Workshop on Cyber-Physical Systems, October, 2006.

CEF - Caixa Econômica Federal. Programa Minha Casa Minha Vida. 2016. Disponível em: <http://www.sinduscon-rio.com.br/mcmv/CARTILHADACAIXA.pdf > Acesso em: 01 de Julho de 2016. 
CHAMUSCA, A. Domótica e Segurança Electrónica : a inteligência que se instala. Ingenium Edições, Portugal, 2006.

CHENG, B. H. C. and ATLEE, M. Research Directions in Requirements Engineering. Proceedings of Future of Software Engineering (FUSE07). IEEE Computer Society, 2007.

DOMINGUES, R.G. A domótica como tendência na habitação: Aplicação em habitações de interesse social com suporte aos idosos e incapacitados. 2013, 147f. Dissertação (Mestrado em Engenharia Urbana) - Escola Politécnica, Universidade Federal do Rio de Janeiro, Rio de Janeiro, 2013.

ELGER, G.; FURUGREN, B. SmartBO - An ICT and computer-based demonstration home for disabled. In: Proceedings of the 3rd TIDE Congress, Helsinki, Finland, 1998.

FERREIRA, V.Z.G. A domótica como instrumento para melhoria da qualidade de vida dos portadores de deficiência. Trabalho de conclusão do Curso Superior de Tecnologia em Automação Industrial do Instituto Federal de Educação, Ciência e Tecnológica da Paraíba. João Pessoa, PB, 2010.

IBGE. PNAD 2013 retrata mercado de trabalho e condições de vida. 2013. Disponível em: $<$ http://saladeimprensa.ibge.gov.br/noticias?view=noticia\&id=1\&busca=1\&idnoticia=2722>.

Acesso em: 06 de Junho de 2016.

JUNG, J.H.; DO, J.H.; KIM, Y.M.; SUH, K.S.; KIM, D.J.; BIEN, Z.Z. Advanced Robotic Residence for the Elderly/the Handicapped: Realization and User Evaluation. Proceedings of the 2005 IEEE 9th International Conference on Rehabilitation Robotics. Chicago, IL, USA, June 28 - July 1, 2005.

NAKATA, T.; SATO, T.; MIZOGUCHI, H.; MORI, T. Synthesis of robot-to-human expressive behavior for human-robot symbiosis. In: Proceedings of the 1996 IEEE/RSJ International Conference on Intelligent Robots and Systems, pp. 1608-1613, 1996.

RAIS. Caracteristicas do emprego formal - Pessoas com deficiencia (PCD). 2013. Disponível em: www.rais.gov.br/. Acesso em: 15 de Janeiro de 2016.

RIBEIRO, C. Dados sobre quedas de idosos no Brasil. 2015. Disponível em: <http://revistavivasaude.uol.com.br/familia/dados-sobre-quedas-de-idosos-no-brasil/4033/\#z. Acesso em: 18 de Abril de 2016.

STEFANOV, D.H.; Bien, Z.; Bang, W. The smart house for older persons and persons with physical disabilities: Structure, technology arrangements, and perspectives. IEEE Trans. on Neural Systems and Rehabilitation Engineering, Vol. 12, No. 2, 228-250, 2004. 